УДК 330.834

ББК 65.02(4Вел)

DOI 10.17150/2308-2588.2017.18(3).488-507

В. А. Успенский

А. Ю. Юданов

Финансовый университет при Правительстве РФ, г. Москва, Российская Федерация

\title{
ДИСКУССИЯ ОБ АВТАРКИИ И ДЖ. М. КЕЙНС: ВСЕ ЕЩЕ АКТУАЛЬНАЯ TЕМА?
}

Аннотация. Рассмотрены аргументы сторонников теории автаркии (национальной самообеспеченности) 1920-1930-х гг., в том числе взгляды Дж. М. Кейнса. Зафиксирована неожиданная актуальность обсуждавшиеся в рамках этой теории проблем (международные экономические санкции, продовольственная, технологическая и военно-политическая безопасность, импортозамещение, влияние курса валюты на ставку процента и другое) для нашего времени. Выявлены особенности позиции Дж. М. Кейнса - ее прагматизм и привязка рекомендуемых мер по ограничению внешнеэкономических связей к ситуациям, в которых оно оправдано мощным внутриэкономическим эффектом. Утверждается, что селективное использование ограничений перспективно и в современных условиях.

Ключевые слова. Автаркия, фритредерство, протекционизм, межвоенный период, наследие Дж. М. Кейнса.

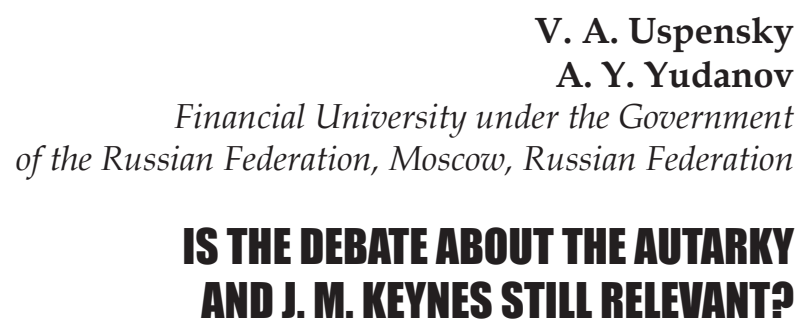

Abstract. The article studies the arguments of the supporters of the autarky theory (national self-sufficien- 
cy) in 1920s-1930s, including views of J. M. Keynes. The author states unexpected relevance of the problems that were discussed in terms of this theory (international economic sanctions, food, technological, military, and political security, import substitution, the impact of exchange rate on interest rate, etc.) for our time. Further, the author considers pragmatism and using recommended measures to limit foreign economic relations only in situations when it will definitely cause powerful economic effect as peculiarities of the J. M. Keynes position. Finally, the author argues that selective use of constraints is effective in the modern world.

Keywords. Autarky (self-sufficiency), free trade, protectionism, interwar period, legacy of Keynes.

\section{1. Концепция автаркии — значимый элемент теории мирохозяйственных связей}

За 80 с лишним лет, прошедших со дня выхода в свет работы Дж. М. Кейнса «Общая теория занятости, процента и денег», судьба макроэкономических воззрений Кейнса претерпевала неоднократные изменения. В разные периоды они вызывали и одобрение, и критику, но из общего дискурса актуальной экономической науки никогда не выпадали. Ни современную макроэкономическую теорию, ни теорию государственного регулирования представить без кейнсианства невозможно. Один аспект воззрений Кейнса, однако, достаточно быстро был предан почти полному забвению, а именно приверженность Кейнса доктрине автаркии или национальной самообеспеченности.

Между тем середина 1930-х гг., время публикации главной работы Дж. М. Кейнса, - это не только период обсуждения среди ученых тяжелейшего кризиса в истории рыночной экономики и не только время опробования первых вариантов государственного антициклического регулирования, сопровождавшегося ожесточенными спорами. Одновременно не менее острая дискуссия касалась системы международных 2017. T. 18, № 3. C. 488-507 
экономических отношений. Традиционное противостояние фритредеров и протекционистов стало столь ожесточенным, что всерьез обсуждалась целесообразность свертывания мирохозяйственных связей.

Сделаем оговорку. На уровне хозяйственной практики протекционизм, включая свои самые жесткие формы, никогда полностью не исчезал из повестки дня экономической политики. Он включал в свою орбиту то одну, то другую страну, чаще - из числа «неудачников» или «отстающих» государств, испытывавших на мировом рынке особенно большие трудности.

Однако на уровне теории после, казалось бы, окончательного научного решения вопроса - а именно после обоснования выгод международного разделения труда (концепции абсолютных и относительных преимуществ Смита - Рикардо) - протекционизм выглядел полностью скомпрометированной, устаревшей теорией. Слом тенденций произошел на рубеже 1920-1930-х годов. Впервые за несколько веков рядом видных экономистов предлагались не просто некие ограничительные меры, но самоизоляция наций. Дж. М. Кейнс принял участие в дискуссии на стороне сторонников автаркии, причем эта тема явно не была для него проходной.

Первые сомнения в правильности традиционных фритредерских (либеральных) подходов посетили его в середине 1920-х гг. (см., например, статью «Экономические последствия валютной политики мистера Черчилля», 1925 г.). В 1933 г. Кейнс публикует программную работу «Национальная самодостаточность» в авторитетном британском журнале The New Stastesman and Nation. Незадолго до этого схожий и также озаглавленный текст публикуется им и в Yale Review. Наконец, проблеме автаркии была посвящена и большая часть главы 23 «Общей теории занятости, процента и денег» (1936 г.).

Участие в формирование концепции автаркии крупнейших ученых, огромная притягательность этой 
парадигмы и серьезность аргументов, выдвигавшихся в ее обоснование, хорошо известны историкам экономической мысли. Но их часто недооценивают экономисты, воспринимающие современную глобализированную экономику как естественное и чуть ли не единственно возможное состояние международных экономических связей. Анализ позиции такого большого ученого, как Кейнс, дает нам хороший повод взглянуть на аргументы забытой теории, тем более, что многие некогда обсуждавшиеся проблемы (санкции, продовольственная, технологическая и военно-политическая безопасность, влияние курса валюты на ставку процента и многое другое) как никогда современны.

\section{2. Концепция автаркии в период расцвета}

Экономический кризис 1929-1933 гг. вызвал в мирохозяйственных связях волну катастрофических процессов: многократное сокращение торговых потоков и вывоза капитала; крах золотого стандарта и последовавшую войну девальваций и таможенных тарифов; дезорганизацию трансграничной системы платежей и ряд иных негативных явлений. В совокупности они обусловили резко отрицательное влияние международных экономических отношений на внутреннюю экономику большинства государств.

К тому же страны все сильнее втягивались в подготовку к приближавшейся мировой войне. Удары извне по национальному хозяйству стали не только болезненными в экономическом смысле, но и абсолютно неприемлемыми в военно-политическом аспекте. В концептуальном плане реакцией на перечисленные угрозы стало становление ${ }^{1}$ доктрины национальной самообеспеченности или автаркии. Эта крайняя разновидность протекционизма приобрела огромную

1 Точнее, новое понимание термина «автаркия», который ранее применялся к античным городам-государствам и был близок по значению к понятию «натуральное хозяйство».

2017. T. 18, № 3. C. $488-507$ 
популярность практически во всех ведущих странах мира.

В США влиятельная Ассоциация внешней политики (Нью-Йорк) утверждала следующее: «Зависимость от продажи товаров за границей представляет тяжелое бремя. Иностранные государства могут в любой момент поднять тарифы или разрешить продажу лишь определенного количества товаров и, таким образом, отрезать нас от важных источников доходов... Иностранные производители, кроме того, могут внезапно выбросить на наши рынки огромные массы продукции и сокрушить наши национальные отрасли промышленности» [7, p. 17]. И подобные взгляды не были единичными в Америке. «Нас захлестнула настоящая волна увлечения экономическим национализмом», резюмировал умонастроения этого времени Ч. Типпетс [15, p.111].

Характерно, что столь остро ситуация воспринималась даже в США несмотря на то, что эта страна обладала огромной и, в силу самого этого факта, в значительной мере самодостаточной экономикой. А ведь Соединенные Штаты были к тому же территориально удалены как от основных конкурентов из Европы, так и от главного театра боевых действий приближавшейся войны.

В Германии внимание обращалось в первую очередь на сферу экономической безопасности с легко прочитываемым подтекстом подготовки войны. Например, за год до прихода нацистов к власти, в 1932 г. на заседании главной комиссии Рейхсфербанда германской промышленности (т. е. союза предпринимателей) видный представитель деловых кругов К. Ламмерс подчеркивал: «Национальная автаркия не представляет собой закрытого для торговли хозяйства... Связи национальной экономики с мировым рынком могут быть допущены при условии, что гарантировано выполнение трех следующих требований: 
1) национальная экономика в случае разрыва связей с мировым рынком должна сохранять жизнеспособность (продовольствие должно производиться в собственной стране);

2) связь с мировым рынком не должна осуществляться за счет интересов германского народа (примат внутреннего рынка);

3) связь национальной экономики ни при каких условиях не должна приводить к политической или экономической зависимости (пример нефти)» [10, s. 8-9].

Задним числом подобные рассуждения легко списать на агрессивность элиты быстро фашизировавшейся страны. Реваншистские устремления были действительно очень сильны в Германии эпохи поздней Веймарской республики. Но трудно не согласиться с тем, что необходимость в достаточном уровне продовольственной самообеспеченности возникала и в других странах (и продолжает возникать в наше время) в качестве важного фактора национальной безопасности при любом росте напряженности международной обстановки.

Показательна и ссылка на нефть. В 1920-1930-е гг., т. е. по тогдашнему популярному выражению в разгар «века моторов», Германия не имела собственных источников этого универсального (автомобили, самолеты, корабли) топлива своего времени. Стоило перекрыть поставки нефти (с чем легко мог справиться британский флот), и германская экономика остановилась бы. Не случайно создание альтернативы нефти производства жидкого синтетического топлива из угля - стало центральной миссией «ИГ Фарбениндустри», германского химического сверхгиганта того времени (по итогам Второй мировой войны он был принудительно демонополизирован и разделен на даже по нынешним меркам огромные «БАСФ», «Байер» и «Хёхст»). 
Особого комментария заслуживает второй пункт требований, касающийся примата внутреннего рынка. Он напрямую связан с повышенной циклической уязвимостью международно-ориентированной экономики. Последнюю было прямо принято выводить из излишней степени специализации. Б. Лаум, крупный теоретик ${ }^{2}$ один из наиболее известных последователей И. К. Родбертуса, писал по этому поводу: «То обстоятельство, что односторонняя специализация усиливает кризисы, постоянно подтверждается опытом... Специализированные фирмы, производящие с помощью специализированных машин специализированные продукты, в большей мере подвержены хозяйственным трудностям, чем имеющие более общий характер и, соответственно, способные более легко перестроиться. К тому же выводу, что излишняя специализация усиливает кризис, а большая универсальность его смягчает, можно прийти и на основе анализа зарубежного опыта. На первое место я ставлю Францию... Своей удивительной устойчивостью к кризисам она обязана тому, что не является односторонне специализированной» [11, s. 467-468].

После прихода в Германии к власти нацистов (1933 г.) автаркия вообще стала частью официальной идеологии страны. Точкой общенационального поворота к ней обычно называют программную речь $Г$. Геринга (на тот момент министр-президента Пруссии, т. е. главы крупнейшей из германских земель) на заседании Прусского ландтага в Берлине 17 декабря 1936 г. В том же году доктрина автаркии нашла практическую реализацию в Четырехлетнем плане развития экономики Германии, разработанный в аппарате Г. Геринг [13]. Можно сказать, что наряду с переводом экономики на военные рельсы автаркия стала основным содержанием этого плана. Официальным уполномоченным

${ }^{2}$ И одновременно убежденный нацист.

2017, vol. 18, no. 3, pp. 488-507 
по реализации плана предсказуемо был назначен все тот же Г. Геринг.

Не меньшую роль автаркия играла в экономической политике фашистской Италии. В 1935 г. после начала Второй итало-абиссинской войны Совет Лиги Наций ввел экономические санкции против этой страны. Был наложен запрет на поставки оружия и некоторых видов стратегического сырья (каучука, свинца, олова, хрома). Кроме того, страны-участники Лиги Наций должны были ограничить импорт товаров из Италии и не предоставлять ей кредитов и займов. Хотя санкции не распространялись на многие ключевые продукты (нефть, уголь, чугун, сталь), а наличие значимых стран, не присоединившихся к ним (в частности, США), в большой мере обесценивало эффективность ограничений, Италия провозгласила переход к полной автаркии. Официально внешнеторговые отношения считались допустимыми лишь с союзными государствами, прежде всего с Германией.

Существенную, хотя и заметно меньшую поддержку идеи автаркии находили во Франции [12]. Даже в Англии, на родине Кейнса и многовековой цитадели фритредерства, многие экономисты полагали «что важнейшей причиной того, что нации стремятся жить своим домом..., является желание избежать неопределенности и дезорганизации, которые они склонны связывать с расширением торговли с другими странами» [6, p. 96].

\section{3. Аргументы Дж. М. Кейнса в пользу автаркии}

В течение жизни взгляды Дж. М. Кейнса претерпели резкий переход от фритредерства к протекционизму. Причем он не только не стеснялся радикальной смены позиции, но и неоднократно подчеркивал отказ от своих первоначальных убеждений: «Моя критика направлена против несостоятельности теоретических основ доктрины laissez-faire, на которой я сам воспиты2017. Т. 18, № 3. С. 488-507 
вался и которой в течение многих лет обучал других» [2, с. 17]. Более того, в зрелых работах Кейнс позволял себе сравнивать фритредерство с религиозными доктринами, способными заставить людей видеть (или истолковывать) даже очевидные вещи не такими, какими они были в действительности.

В работах Кейнса, если смотреть на них глазами современного (вновь фритредерского) мейнстрима, сплошь и рядом встречаются шокирующие позиции. Фактически весь вышеописанный нами репертуар аргументов сторонников автаркии присутствует в трудах Дж. М. Кейнса. Это и надежды с помощью таможенных тарифов сократить британскую безработицу, и опасения враждебной экономической политики других стран. И уверенность в благотворности опоры на собственные силы: «Мы нуждаемся в том, чтобы быть настолько свободными, насколько это возможно, от всех экономических изменений где-либо, чтобы осуществить избранный нами самими эксперимент (имеется в виду британский путь развития. - Авт.). А движение по пути к большей национальной самообеспеченности и экономической изоляции сделает нашу задачу проще» [8, p. 65].

Вместе с тем причины приверженности Кейнса идеям автаркии, на наш взгляд, глубже, чем у большинства придерживавшихся изоляционистских убеждений современников. Прежде всего, он подвергает сомнению, казалось бы, незыблемый, неоспоримый даже в глазах оппонентов фундамент фритредерства представления о выгодах международного разделения труда. Точнее, Кейнс не сомневался в существовании этих выгод в XVIII-XIX вв., когда и были разработаны теории абсолютных и относительных преимуществ. Более того, в качестве константы, справедливой на все времена, Кейнс признает необходимость «определенного уровня международной специализации», обусловленного естественными причинами (различиями 
климата, неравномерным распределением природных ископаемых и пр.).

Однако, по его мнению, применительно к более развитой экономике конца первой трети $\mathrm{XX}$ в. в своем основном содержании ситуация радикально изменилась. «Накапливаются доказательства, что большинство современных процессов массового производства могут быть реализованы в большинстве стран и климатических условий практически с одинаковой эффективностью» [9, р. 761]. Страновых конкурентных преимуществ, а значит, и преимуществ в разделении труда между странами, при такой постановке вопроса просто не может быть, во всяком случае, не может быть в современном секторе экономики.

В новой реальности смитианский-рикардианский взаимовыгодный обмен английской шерсти на португальское вино перестает быть самоочевидным аргументом в пользу внешнеэкономического сотрудничества. Ведь производственный потенциал ведущих стран отныне олицетворяют не резко отличающиеся в разных странах природные пастбища и виноградники, а повсеместно похожие автосборочные конвейеры и химические реакторы, которые могут быть эффективно организованы в любой из стран.

Применительно к нашему времени подобные рассуждения звучат, пожалуй, еще более весомо, чем тогда, когда они высказывались Кейнсом. Легко видеть, что экономическая история последних десятилетий дала мощное эмпирическое подтверждение реалистичности его теоретических построений. Не слишком богатый природными ресурсами, не имевший (по меньшей мере, первоначально) квалифицированной рабочей силы и безнадежно отстававший от технологических лидеров Китай смог наладить производство практически всех современных товаров, превратившись во вторую после Великобритании «мировую фабрику» в истории человечества. 
Именно эта тотальность освоения производства чуть ли не всего спектра продуктов значима в свете аргумента Кейнса: применительно к сфере господства современных технологий не находится ни одного товара, производство которого нельзя бы было при разумной постановке дела эффрективно - это ключевое слово! - организовать внутри одной страны (в данном случае в Китае).

Разумеется, современный Китай менее всего похож на автаркическое хозяйство. Несомненно, что успехи этой страны никогда не реализовались бы без беспрецедентного импорта капитала и технологий, равно как и без экспортно-ориентированной модели роста. Но факт остается фактом: не имевшая исходных значимых преимуществ страна сумела наладить полный цикл современных конкурентоспособных производств: от первых переделов сырья до финишной сборки готовых продуктов. Как это ни парадоксально, открытый и повернутый к миру Китай способен сам удовлетворять собственные потребности в столь высокой степени, которую на практике редко удавалось достичь наиболее ориентированным на автаркию режимам прошлого.

Не утратил, а скорее только нарастил свою значимость и другой аргумент Кейнса против преимуществ международного разделения труда. В современной терминологии его можно передать как увеличение в современной экономике доли так называемых неторгуемых товаров (non-tradable goods), не принимающих участия в международной торговле. Этот процесс виделся Кейнсу прямым результатом расширения сферы услуг, по самой своей природе не поддающихся транспортировке: «Более того, с ростом богатства (наций. - Авт.) как первичные, так и промышленные товары занимают меньшую долю в сравнении с [услугами] жилищ, персональными услугами, местными достопримечательностями, которые не находятся в 
международном обмене» [9, р. 761]. А ведь со времен Кейнса третичный сектор только рос и рос, все более тесня первичный и вторичный сектора!

Еще одно отличие Кейнса от других сторонников автаркии, по нашему мнению, состоит в том, что он смотрел на проблему глазами первого теоретика государственного антикризисного регулирования и потому стремился выявить влияние внешнеэкономических связей на параметры макроэкономического равновесия в стране. Он, например, писал: «Внутреннюю экономическую политику часто было бы легче проводить, если бы удалось взять под контроль феномен, известный как “бегство капиталов" » [8, р. 37].

Кейнс, вероятно, первым обратил внимание на то, что ключевая для его теории категория ставки процента может отклоняться от оптимального для экономики уровня в связи с внешнеэкономическим воздействиями. «За последнее время лондонские банкиры-практики многому научились, и можно почти надеяться, что в Великобритании больше никогда не будут пользоваться методом регулирования банковского процента для защиты платежного баланса в таких условиях, когда это может породить безработицу внутри страны» [2, с. 290]. В этих словах отчетливо провозглашается приоритет внутриэкономических целей над внешнеэкономическими целями.

Вероятно, от ученого, творившего в эпоху Великой депрессии, иного нельзя было ожидать. Невиданный по глубине и длительности кризис, поставивший под вопрос само существование капиталистической экономики (ни до, ни после него так жестко вопрос выживания рыночной системы не стоял), практически не оставлял выбора, чем жертвовать. Если Кейнс и надеялся на восстановление мирохозяйственных связей, то ожидал его в качестве косвенного результата оздоровления внутри национальной экономики. Он писал: «Именно политика независимой нормы процента, 2017. T. 18, № 3. C. 488-507 
не нарушаемой соображениями международных отношений, и (политика. - Авт.) осуществления программы национальных инвестиций, направленной на достижение высокого уровня внутренней занятости, дважды благословенна потому, что она одновременно помогает и нам, и нашим соседям» [2, с. 299].

\section{4. Про-автаркическая концепция Кейнса и наше время}

Примерно с конца 1950-х гг. теории автаркии постепенно утратили популярность. В наше время (если не считать буквально двух-трех последних лет) ее приверженцы и вовсе не рассматриваются в экономической науке всерьез. Как удачно выразился один современный экономист, оценка числа инакомыслящих теоретиков (dissenting economists) в этой области колеблется от «редки» до «не существуют» [16]. То, что к числу инакомыслящих принадлежал великий Кейнс вообще, как правило, не вспоминается. Экономисты, вновь вернувшие в свои учебники апологию свободы торговли, обычно трактуют (реже в прямой форме, а чаще по умолчанию) современную непопулярность доктрины автаркии как результат ее содержательного краха, как следствие слабости аргументов в ее пользу.

Однако представляется, что при таком подходе недостаточно учитываются долговременные исторические тренды. Процесс интернационализации экономической жизни не направлен в одну сторону. И господствующие в этой сфере долговременные тенденции не могут не оказывать влияния на течения экономической мысли. Аргументы в пользу фритредерства звучат крайне неубедительно, когда мирохозяйственный комплекс катастрофически свертывается. Напротив, распространение автаркических взглядов крайне сомнительно в эпоху длящегося десятилетиями стремительного расширения внешнеэкономических связей. 
Таблица

Историческая динамика экспортной квоты крупнейших развитых стран (экспорт в \% к ВВП)

\begin{tabular}{|l|c|c|c|c|c|c|c|c|}
\hline Страна & $\begin{array}{c}\text { До } \\
\text { Первой } \\
\text { мировой } \\
\text { войны }\end{array}$ & \multicolumn{3}{|c|}{$\begin{array}{c}\text { Межвоенный } \\
\text { период }\end{array}$} & \multicolumn{3}{|c|}{$\begin{array}{c}\text { После Второй } \\
\text { мировой войны }\end{array}$} & $\begin{array}{c}\text { XXI } \\
\text { в. }\end{array}$ \\
\cline { 2 - 11 } & 1913 & 1928 & 1932 & 1938 & 1950 & 1960 & 1981 & 2015 \\
\hline США & 12,9 & 6,3 & 4,0 & 4,8 & 3,9 & 4,0 & 8,0 & 9,3 \\
\hline Япония & - & 14,0 & 14,0 & 11,7 & - & 9,8 & 13,5 & 14,8 \\
\hline Германия & 23,8 & 17,6 & 13,4 & 7,0 & 11,0 & 20,0 & 25,6 & 39,2 \\
\hline $\begin{array}{l}\text { Великобри- } \\
\text { тания }\end{array}$ & 23,9 & 22,2 & - & 15,4 & 22,0 & 20,0 & 19,3 & 17,2 \\
\hline Франция & 19,1 & - & - & 11,8 & 16,0 & 15,0 & 18,6 & 20,5 \\
\hline
\end{tabular}

Рассчитано по: Helander S. Das Autarkieproblem in der Weltwirtschaft. Berlin, 1955. S. 33-47; Union Bank of Switzerland. Switzerland in Figures. 1962. P. 6; 1982. P. 6-7; 2016. P. 6-7.

В Табл. длительные волны экспансии и сжатия мирохозяйственных связей отчетливо видны на примере развития внешней торговли за последние сто лет. Перед Первой мировой войной значение экспорта для экономики важнейших развитых стран было колоссальным. Бросается в глаза, что, несмотря на отсутствие нынешних средств связи и транспорта, размеры экспортной квоты в целом были сопоставимы с современными, а в некоторых странах (в частности, в США и Великобритании) даже превосходили их. Не удивительно, что фритредерство в ту эпоху господствовало практически безраздельно. Последовавшее далее двукратное / трехкратное снижение экспортной квоты между двумя мировыми войнами вряд ли случайно совпало с описанным выше периодом торжества доктрин автаркии. Наконец, длящееся вплоть до нашего времени усиление интенсивности внешнеэкономических связей делает новый триумф идей самоизоляции маловероятным. Неоднозначность развития мировой 2017. T. 18, № 3. C. 488-507 
экономики в самые последние годы заслуживает особого обсуждения (см. ниже), но очевидно, что преуспеяние наций, отраслей и отдельных фирм в наше время прямо зависит от их способности добиваться успеха на мировом рынке.

И все же представляется, что в научном плане нельзя отмахнуться от проблем, обсуждавшихся в знаменитой дискуссии об автаркии, лишь потому, что тотальная самоизоляция стран сегодня не актуальна. Излагая позиции сторонников автаркии и, в особенности, соображения Дж. М. Кейнса, мы стремились продемонстрировать, что они отнюдь не являются беспочвенными и по современным представлениям.

Особенно привлекает прагматизм Кейнса. Вернемся к тому, с чего начиналась статья, а именно к публично признававшемуся Кейнсом радикальному изменению его взглядов на фритредерство и протекционизм. Чем мотивировал он смену позиции? «Снова вглядываясь сейчас в положения тех фундаментальных истин (имеются в виду фритредерские взгляды. - Авт.), которых я придерживался тогда, я не ощущаю желания оспаривать их. Однако мои взгляды переменились; и со мной эту перемену разделяют многие другие. Отчасти это связано с изменением моих экономико-теоретических воззрений (background of economic theory)... Но в основном я связываю смену с чем-то иным... По крайней мере сейчас, прожив треть двадцатого столетия, большинство из нас [ментально] покидает столетие девятнадцатое» [9, р. 755].

Кейнс сравнивает соотношение рисков и выгод свободы торговли, каковыми они были в XIX в. и каковыми стали в наиболее кризисный период XX в. И отказывается от фритредерства не из теоретического пуризма, а потому, что $b$ конкретных условиях фритредерские рекомендации становятся самоубийственными. У Кейнса нет идеализации свободы торговли, как нет и идеализации автаркии, но лишь выбор страте- 
гии, представляющейся оптимальной в определенной ситуации. «Национальная самообеспеченность, если быть кратким, хотя и стоит неких расходов, но представляет собой роскошь, которую мы можем позволить себе, если сочтем это нужным» $[9, \text { р. 761 }]^{3}$.

Вопрос, по его мнению, состоит, следовательно, не столько в необходимости выбора между фритредерством и автаркией, сколько в том, применительно к каким конкретным целям имеет смысл избрать инструменты той или другой заведомо неидеальной стратегии. И в этом, более узком смысле давние рекомендации Дж. М. Кейнса, по нашему мнению, приобретают вполне современное звучание.

Практически каждый раз, когда господствующее фритредерское отношение к мирохозяйственным связям сталкивается с кейсами внутрихозяйственных трудностей, порождаемых именно открытостью экономики, альтернативные теории обращаются к наследию Кейнса. Например, вполне протекционистское по своему содержанию требование существенно ограничить сферу международных финансовых / биржевых операций (вспомним упоминавшееся выше пожелание Дж. М. Кейнса «взять под контроль феномен, известный как “бегство капиталов"») была общим местом в рекомендациях по преодолению кризиса 2008-2009 гг. Более радикальные предложения простирались на ограничение восточноазиатской, в частности, китайской экспортной экспансии. Не случайно, обзор этих предложений, сделанных канадским экономистом

${ }^{3}$ Интересно, что схожую аргументацию много позже (в 1978 г.) практически дословно повторил такой авторитетный сторонник развития мирохозяйственных связей как Ч. Киндлебергер: «Это не значит, конечно, что протекционизм является наилучшим путем защиты попавших под угрозу рабочих мест и доходов, но это значит, что протекционизм может быть в такие времена лучшим выходом, чем другая политически легко реализуемая альтернатива, состоящая в том, чтобы не делать ничего» (цит. по: [16]). 
М. Воткинсом, вышел под характерным заглавием «Кейнс и национальная самодостаточность. Не слишком ли много стало [внешней] торговли?» [16].

А совсем недавно крупный французский экономист Ж. Сапир провел прямую связь между воззрениями Кейнса и экономической программой нового президента США Д. Трампа [14, р. 68]. Не подозревая последнего в глубоком «знании истории феномена», Ж. Сапир полагает, что объективно Д. Трамп, «бросая вызов ортодоксии фритредерства», открывает новое окно возможностей для политики, нацеленной на создания сильного государства развития» [14, р. 69].

Избирательность вообе характерна для современного отношения к применению кейнсианского инструментария за пределами тех ситуаций, для которых их предназначал сам Кейнс. Особенно важным это, вероятно, является при попытках использовать наследие Кейнса в современной России (обсуждение применимости кейнсианства в современной России см. [1; 3; 4; 5]). Приведем лишь один пример.

Когда в сложной депрессивной обстановке 2014 г. упали цены на нефть и начался обвал курса рубля, Банк России поднял ключевую ставку процента до $17 \%$, остановив девальвацию, но и нанеся сокрушительный удар по и без того слабой внутренней деловой активности страны. В частности, при новом уровне ставок возможности внешнего финансирования малого и среднего бизнеса были перекрыты. Ведь при кредитовании этих, не являющихся первоклассными заемщиков, типичная ставка превышала 30 \%, но еще чаще в выдаче кредита таким предприятиям и организациям вообще отказывалось.

Фактически Банк России сделал ровно то, от чего предостерегал Кейнс: стал во время кризиса проводить политику дорогих денег ради поддержания курса валюты. Чем мотивировалось решение регулятора? Официальным таргетом Банка России является по- 
нижение инфляции до уровня 4 \% в 2017 г. Но фактически диктовать уровень инфляции Банк России не в состоянии - слишком значимы в современной российской экономике немонетарные факторы. Инфляция не столько таргетируется, т. е. целеполагается на определенном уровне, а потом усилиями Банка России достигается, сколько с большим или меньшим успехом прогнозируется.

Реальный же выбор сценария быстрого или, напротив, медленного снижения современной, откровенно препятствующей росту экономики ключевой ставки кредитования, как следует из публикаций самого Банка России, напрямую завязываются на внешнеэкономическую ситуацию и, в частности, на цену нефти. Так, в «Докладе о денежно-кредитной политике» за 2015 г. говорится: «Банк России по-прежнему рассматривает наряду с базовым сценарием оптимистичный и рисковый сценарии. Основное отличие данных сценариев заключается в динамике цен на нефть» ${ }^{4}$.

Между тем, чем дальше, тем более очевидным становится, что возвращение России на траекторию экономического роста стало экзистенциальным вызовом для нашей страны. И одним из главных препятствий на этом пути является завышение ключевой ставки процента. Не стоит ли вслед за Дж. М. Кейнсом задуматься над тем, в каких случаях следует «счесть нужным» оплатить «роскошь» приоритетности целей внутреннего развития над целями внешнеэкономическими?

\section{Өписок использованной литературы}

1. Дзарасов С. С. Куда Кейнс зовет Россию? / С. С. Дзарасов. - М. : Алгоритм, 2012. - 304 с.

2. Кейнс Дж. М. Общая теория занятости, процента и денег / Дж. М. Кейнс ; пер. с англ. - М. : Гелиос, 2015. - 352 с.

${ }^{4}$ Доклад о денежно-кредитной политике // Информационно-аналитический сборник. М. : Банк России, 2015. № 4 (12). С. 3-4. 2017. T. 18, № 3. C. 488-507 
3. Маневич В. Е. Кейнсианская теория и российская экономика / В. Е. Маневич. - М. : КомКнига, 2010. - 224 с.

4. Найденова Е. М. Рузвельт, Кейнс и Великая депрессия / E. М. Найденова // TERRA ECONOMICUS. - 2013. - T. 11, № 4 . - С. 36-43

5. Ядгаров Я. С. «Кейнсианская революция» в зеркале «нового курса» Ф. Д. Рузвельта / Я. С. Ядгаров // Историко-экономические исследования. - 2013. - Т. 14, № 3. - С. 37-48.

6. Asher P. H. National Self-Sufficiency / P. H. Asher. - L. ; N. Y. : T. Nelson, 1938. - 188 p.

7. Goslin R. A. Made in USA / R. A. Goslin. - N. Y. : The Foreign Policy Association, 1935. - $38 \mathrm{p}$.

8. Keynes J. M. National Self-Sufficiency / J. M. Keynes // The New Stastesman and Nation. - 1933. - N 8. - P. 35-68.

9. Keynes J. M. National Self-Sufficiency // The Yale Review. - 1933. - Vol. 22, no. 4. P. 755-769.

10. Lammers C. Autarkie, Planwirtschaft und berufsständischer Staat? / C. Lammers. - Berlin : Carl Heymann Verlag, 1932.

11. Laum B. Die geschlossene Wirtschaft. Soziologische Grundlegung des Autarkieproblems / B. Laum. - Tübengen : Mohr,1933. - $255 \mathrm{~s}$.

12. Novak J. L'idée de l'autarcie économique / J. Novak. - P., 1925.

13. Petzina D. Autarkiepolitik im Dritten Reich. Der nationalsozialistische Vierjahresplan / D. Petzina. - Stuttgart, 1968. - (Schriftenreihe der Vierteljahrshefte für Zeitgeschichte Nr. 16).

14. Sapir J. President Trump and free trade [Electronic Resource] / J. Sapir / / Real-World Economics Review. - 2017. Issue 79. - P. 64-73. - Access mode : http://www.paecon.net/ PAEReview/issue79/Sapir79.pdf.

15. Tippetts Ch. S. Autarchy : National Self-Sufficiency / Ch. S. Tippetts. - Chicago : University of Chicago Press, 1933. $26 \mathrm{p}$.

16. Watkins M. Keynes and «National Self-Sufficiency». Is There Too Much Trade? [Electronic Resource] / M. Watkins // Canadian Dimension. 2009. June 6. - Access mode : https:// canadiandimension.com/articles/view/web-exclusive-keynesand-national-self-sufficiency

\section{Информация об авторах}

Успенский Владимир Анатольевич - кандидат экономических наук, доцент, департамент экономической теории, 
Финансовый университет при Правительстве РФ, 125993, г. Москва, Ленинградский проспект, д.49, e-mail: wowaus@ skypoint.ru.

Юданов Андрей Юрьевич - доктор экономических наук, профессор, департамент экономической теории, Финансовый университет при Правительстве РФ, 125993, г. Москва, Ленинградский проспект, д.49, e-mail: yudanov@yandex.ru.

\section{$\$ \pi$}

Vladimir A. Uspensky - Ph.D. in Economics, Associate Professor, Department of Economic Theory, Financial University under the Government of the Russian Federation, 49, Leningradsky Prospekt, Moscow, Russian Federation, 125993, e-mail: wowaus@skypoint.ru.

Andrei Y. Yudanov - D.Sc. in Economics, Professor, Department of Economic Theory, Financial University under the Government of the Russian Federation, 49, Leningradsky Prospekt, Moscow, Russian Federation, 125993, e-mail: yudanov@ yandex.ru.

\section{Для цитирования}

Успенский В. А. Дискуссия об автаркии и Дж. М. Кейнс: все еще актуальная тема? / В. А. Успенский, А. Ю. Юданов // Историко-экономические исследования. 2017. - T. 18, № 3. - C. 488-507. - DOI: 10.17150/23082588.2017.18(3).488-507.

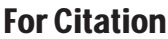

Uspensky V. A., Yudanov A. Y. Is the Debate about the Autarky and J. M. Keynes Still Relevant? Istoriko-ekonomicheskie issledovaniya = Journal of Economic History $\mathcal{E}$ History of Economics, 2017, vol. 18, no. 3, pp. 488-507. DOI: 10.17150/23082588.2017.18(3).488-507. (In Russian). 